\title{
A JUSTIÇA RESTAURATIVA COMO PROCESSO EDUCATIVO DE RESISTÊNCIA AO ITINERÁRIO PENALIZADOR DIRIGIDO AOS JOVENS DA PERIFERIA URBANA
}

\author{
RESTORATIVE JUSTICE AS AN EDUCATIONAL RESISTENCE PROCESS TO THE \\ PENALIZER MODEL RELATED TO YOUNG PEOPLE OF URBAN PERIPHERY
}

\author{
Cezar Bueno de Lima* \\ Lindomar Wessler Boneti ${ }^{\star *}$
}

\begin{abstract}
Resumo
O objetivo do artigo é compreender o fenômeno da violência juvenil urbana a partir de reflexões teóricas que evitam explicações monocausais da violência e da erosão da lei sem, entretanto, ocultar ou menosprezar o fato de os jovens oriundos das classes sociais subalternas constituírem o núcleo preferencial da atuação policial e do sistema de justiça juvenil. O estudo sugere a necessidade de implementação do modelo de justiça restaurativa como processo educativo vinculado à produção de saberes, experiências e decisões numa dimensão participativa entre os atores e órgãos implicados no processo, como estratégia de construção da autonomia e solução pacífica dos conflitos, alinhada à defesa e promoção dos direitos humanos.
\end{abstract}

Palavras-chave: Violência Juvenil. Desigualdade. Direitos Humanos. Justiça Restaurativa.

\begin{abstract}
The objective of the article is to understand the phenomenon of urban youth violence from the description of some characteristics of public policies for social inclusion and forms of sociojudicial control in an open environment, for young people in conflict with the law. The work avoids monocausality analysis in explaining the violence and the erosion of law without, however, hide or downplay the fact that young people from the subaltern classes constitute the preferred core of the police action and the juvenile justice system. The study suggests the need to implement the restorative justice model as an educational process linked to production of knowledge, experiences and decisions in a participatory dimension as the involved actors and agencies in the process, as building strategy of autonomy and peaceful resolution of conflicts in line with defense and promotion of human rights.
\end{abstract}

Keywords: Youth Violence. Inequality. Human rights. Restorative Justice.

\section{Introdução}

As reflexões deste artigo são parte de estudos e pesquisas em desenvolvimento ${ }^{1}$ que buscam identificar e estabelecer pontos de conexão e interpendência entre Direitos Humanos e a construção de espaços de participação e deliberação juvenil como forma de mediação e prevenção

\footnotetext{
* Doutor em Ciências Sociais. Professor do Programa de Pós-Graduação em Direitos Humanos e Políticas Públicas da PUCPR. E-mail: czarbueno@gmail.com

${ }^{* *}$ Doutor em Ciências Sociais. Professor do Programa de Pós-Graduação em Direitos Humanos e Políticas Públicas da PUCPR. E-mail: lindomar@boneti.com

1 Os estudos e pesquisas estão vinculados à linha de pesquisa Políticas Públicas e Educação em Direitos do Programa de Pós-Graduação em Direitos Humanos e Políticas Públicas da PUCPR.
} 
pacífica dos conflitos no espaço escolar. O objetivo do artigo é analisar o contexto penalizador da juventude na condição de pobreza e outras vulnerabilidades sociais compreendidas como expressão da questão social, portanto, da desigualdade entre as classes, das frágeis respostas estatais e atuação das forças sociais democráticas em defesa dos direitos humanos. O desafio do artigo é oferecer conceitos e argumentos teóricos que contribuam à compreensão do mundo de vida da juventude pobre e à realização de políticas públicas, como é o caso da justiça restaurativa, como forma de reverter o histórico de violência e exclusão social que recai sobre os jovens pobres na mira das instituições de controle; especialmente, entre os adolescentes jovens inseridos no contexto da pobreza e vulnerabilidade social, penalizados pela cultura de repressão dos aparatos de Estado e de outras instâncias institucionais.

A perspectiva de análise adotada questiona a legitimidade teórica e conceitual das abordagens funcionalistas, "psicologizantes" e culpabilziadoras, por entender que estas, sem se reportarem a situações e conjunturas sociais marcadas por assimetrias no tocante à posse de capital econômico, político, educacional, entre outros, se limitam a compreender e explicar a juventude como uma etapa de vida homogênea, caracterizada pela existência de problemas comuns. Ou, ainda, quando propõem explicar as perturbações juvenis com base na estratificação de faixa etária e aspiração comum em termos de preferências valorativas, consumo cultural e projeto de vida.

A análise realizada a partir do referencial da teoria social crítica dos direitos humanos sugere que as formas de controle da violência juvenil urbana são, em grande medida, caracterizadas pela institucionalização de práticas oficiais que buscam, via de regra, justificar suas ações com base na produção de verdades divulgadas na mídia comercial e extraída de preceitos morais das pessoas comuns, inseridas na rotina do trabalho na indústria, no comércio, na prestação de serviços, na administração pública, entre outros. O fortalecimento do paradigma fundado no binômio punição-prisão decorre do processo de naturalização das desigualdades material e simbólica que excluem e marginalizam contingentes significativos da juventude brasileira. Assim, a força moral do discurso punitivo tende a pavimentar o caminho de políticas governamentais violadoras dos direitos humanos juvenis e, por extensão, os de suas famílias e de seus territórios marcados pelo estigma da pobreza e desobediência à lei.

Ao lado do processo das desigualdades estruturais que caracterizam a formação da sociedade brasileira, o país vem presenciando, sobretudo, a partir dos anos noventa do último século, o aprofundamento do olhar e julgamento moral em relação à pobreza, cujo reflexo, em termos de exclusão, segregação e intolerância social, torna-se mais visível entre os sujeitos que habitam territórios precarizados e marcados pelo estigma da incivilidade urbana.

\section{Desigualdades sociais, pobreza e violência juvenil na era do capitalismo globalizado}

A leitura de autores como Passetti (2003) e Wacquant (2015) permite inferir que a passagem dos anos de 1980-90 constitui o ponto de inflexão e de elevação do julgamento moral 
desabonador das classes média e alta em relação aos indivíduos oriundos das classes sociais precarizadas. No período em questão, houve o aprofundamento da percepção social negativa que, antes, conferia o benefício moral de os indivíduos das classes sociais subalternas aderirem, não apenas à visão de mundo e de consumo difundidos no universo das classes médias urbanas mas, por assim dizer, maior liberdade de os primeiros transitarem juntos às segundas, sem $o$ rótulo da suspeição generalizada. As pessoas das classes socialmente incluídas pareciam conferir aos pobres uma espécie de crédito simbólico, concedendo-lhes o benefício moral do bom comportamento, da disciplina ao trabalho, do respeito à ordem legal estabelecida, incluindo a possibilidade de estabelecerem relações de proximidade físico-espacial nos territórios habitados pelas classes médias. Essa concepção moral virtuosa, em relação à pobreza, tende a se dissipar progressivamente no transcorrer dos anos de 1990.

Neste período, escreve Passetti (2003, p.171-172), a ampliação das desigualdades sociais e a deterioração da crença no monopólio estatal de controle da violência e do crime, resultado da "retração do Estado-de-bem-estar social [para a] hegemonia do Estado policial, penalizador", altera o sentimento das classes média e alta em relação aos habitantes da periferia, levando as primeiras a exigir "maior segurança, capaz de protegê-la dos sangue-ruins [e] dos incômodos provocados pelos chamados desajustados". O olhar de ceticismo dirigido aos setores sociais precarizados pressiona os governos a redefinirem as políticas de segurança. A este respeito, argumenta Passetti:

[As instituições de Estado que, antes, identificavam certos locais] como a cultura da pobreza, de comportamentos socialmente não aceitos permitindo, porém certo trânsito [dos pobres] com a sociedade maior, [passaram, nos anos 90, a defini-los] como áreas urbanas problemáticas, proibidas, circuitos selvagens, territórios de abandono (...) locais de vícios, violência, excesso de crime e desintegração social (2003, p. 171).

No mesmo período, comenta Wacquant (2001, p.48), a ascensão de partidos e correntes políticas conservadoras nos países capitalistas avançados ou em desenvolvimento, como o Brasil, amplia os canais de produção e circulação dos discursos morais que vinculam a condição de pobreza "ao comportamento dos pobres". Apesar de o contexto econômico-político neoliberal conferir maior visibilidade aos movimentos sociais que reivindicam a quebra de identidades fixas no sentido de torná-las plurais, "indeterminadas e indetermináveis", o período em questão, escreve Bauman (2007, p.45), apresenta sinais inequívocos de aumento da desigualdade econômica e deterioração das políticas governamentais de defesa e proteção de direitos humanos.

Segundo Wacquant (2001, p.48 e 62), o descolamento do debate das políticas estruturais distributivas para o terreno do comportamento individual não se limita a imputar "as causas das incivilidades" e do crime à ação individual. Sob pressão das forças econômico-financeiras e de governos comprometidos com a gestão de políticas neoliberais de eliminação ou retração de direitos sociais, as novas estratégias de gestão e controle criminal das desigualdades sociais, 

ao itinerário penalizador dirigido aos jovens da periferia urbana

afirma Lima (2009, p.49-50), ordenam maior "responsabilização dos pobres subvencionados pelo Estado". Este é o caso do Decreto Presidencial no 8.118 , de outubro de 2013, ao estipular que o "trabalhador que solicitar o benefício a partir da segunda vez, dentro de um período de dez anos, terá que fazer curso com o mínimo de 160 horas para receber o pagamento". Em face dos processos engendradores de desigualdades econômico-sociais, os governos buscam criar mecanismos legais que preveem maior disciplina, constrangimento ao trabalho e diminuição da alegada cultura da dependência.

Na esfera político-criminal, adverte Wacquant (2003, p.7-8), o pensamento hegemônico neoliberal dos anos 90 abriu caminho para as reformas políticas que transformaram o sistema penal numa "espécie de território sagrado da nova ordem socioeconômica global". A mídia comercial privada se consolidou como ator social capaz de pautar o discurso político e evidenciar sua força ao fazer com que a luta pela "hegemonia do discurso criminológico [ocorra] na esfera das comunicações". Doravante, os discursos da penalização representam um componente permanente "da paisagem urbana" e são compartilhados nos espaços de interação da vida cotidiana, incluindo desde a base social ao nível local, à mídia comercial, aos agentes políticos, aos expedientes burocráticos e às universidades. (WACQUANT, 2015, p.28).

No campo da correlação de forças político-jurídicas internas a atual Constituição e o Programa Nacional de Direitos Humanos (PNDH) são confrontados por ideologias políticomorais e religiosas e pela irradiação de discursos midiático-penais e populistas, com a pretensão de inculcar a cultura da ordem e do medo e legitimar práticas institucionais de violação dos direitos humanos. Entretanto, o apelo político-moral às ideologias em questão é contrariado por evidências teórico-empíricas que apontam “[...] uma estreita e positiva correlação entre a deterioração do mercado de trabalho e o aumento dos efetivos presos - ao passo que não existe vínculo algum comprovado entre índice de criminalidade e índice de encarceramento" (WACQUANT, 2001, p.107).

A ideologia política encarceradora parece ter abandonado a importância de iniciativas de políticas econômico-sociais, educacionais e profissionalizantes de prevenção da violência e de penalização do espaço social urbano, como preveem a atual Constituição e o PNDH3. Informações produzidas pelo Departamento Penitenciário Nacional (DEPEN) mostram que:

[No ano de 2016] existiam 726.712 pessoas privadas de liberdade no Brasil, [...]. Em relação ao número de vagas, observamos um déficit total de 358.663 mil vagas [cifra que] representa um aumento da ordem de $707 \%$ em relação ao total registrado no início da década de 90. [Quanto à situação jurídica dos encarcerados], 40\% das pessoas presas no Brasil em junho de 2016 não haviam sido ainda julgadas e condenadas. (DEPEN, 2016, p.8-13).

Na mesma direção, o relatório divulgado pela ONG Human Rights Watch, acerca da letalidade da polícia nos estados de São Paulo e Rio de Janeiro, conclui que "uma parte significativa das mortes relatadas como resistência seguida de morte ou autos de resistência em 
ambos os estados se trata de fato de casos de execuções extrajudiciais" (HRW, 2009, p.2). No tocante à população juvenil brasileira, os territórios urbanos que abrigam os jovens pobres não estão imunes à ação letal da polícia. Segundo Waiselsz, o assassinato por armas de fogo no Brasil:

[...] passou de 4.415 vítimas em 1980, para $24.882 \mathrm{em} \mathrm{2012.} \mathrm{[Ou} \mathrm{seja],} \mathrm{463,6 \%} \mathrm{de} \mathrm{au-}$ mento nos 33 anos decorridos entre as datas. (...) Entre os jovens de 15 a 29 anos, esse crescimento foi ainda maior: passou de 4.415 vítimas em 1980, para $24.882 \mathrm{em} \mathrm{2012:}$ $463,6 \%$ de aumento [no período]. (WAISELSZ, 2015, p.21).

Em países que apresentam elevadas taxas de desigualdades sociais e cultura policial repressiva, a promoção de políticas públicas como corolário dos direitos humanos tende a se esbarrar com processos de naturalização da ação violenta da polícia, sobretudo, contra os adolescentes e jovens precarizados, e fazer com que a atuação policial à margem da lei seja vista e avaliada pela sociedade ora com indiferença, ora como corretivo moral.

\section{Violência juvenil, penalização do espaço urbano e direitos humanos}

Nos territórios urbanos precarizados, argumenta Wacquant, ao lado dos estigmas tradicionalmente "operantes ligados à pobreza", à pertença étnica e à imigração, o local de moradia constitui uma desvantagem adicional no sentido de "desqualificar um indivíduo e privá-lo da total aceitação pelos outros”. A este respeito, pouco importa o fato de saber:

[Se] os lugares onde [os indivíduos] vivem estejam ou não deteriorados, sejam ou não perigosos e a sua população seja ou não essencialmente composta de pobres, minorias e estrangeiros. A crença preconceituosa de que assim são basta para engendrar consequências socialmente nocivas. (WACQUANT, 2015, p.29).

Uma das estratégias para atenuar o sentido de indignidade social nos bairros relegados é transferir "o estigma para outra entidade diabolizada e sem rosto - os vizinhos de baixo, a família imigrada que mora no prédio ao lado, os jovens do outro lado, etc". Wacquant argumenta que a "lógica da difamação lateral" e do distanciamento mútuo opera no sentido de dissolver ainda mais os "coletivos já enfraquecidos das zonas urbanas deserdadas". A estigmatização territorial, além de perpetrar a crença desabonadora nos espaços definidos como "zonas de não direito e cidade fora da norma", funciona como álibi para as autoridades justificarem a criação de "medidas especiais, derrogatórias", com o pretexto de coibir supostas incivilidades. Esta modalidade de intervenção governamental amplia o quadro de desestabilização e de marginalização dos habitantes locais no sentido de submetê-los "aos ditames do mercado de trabalho desregulado, torná-los invisíveis ou escorraçá-los de um espaço cobiçado" (WACQUANT, 2015, p.29-30)

As políticas neoliberais de gentrificação urbana constituem outro aspecto a ser considerado. A privatização do espaço urbano, sob a forma de condomínios fechados, contribui 

ao itinerário penalizador dirigido aos jovens da periferia urbana

para erodir o sentimento de partilha comum do território e esfacelar o ideal republicano de espaço público aberto e acessível a todos. A proliferação de enclaves urbanos, do trabalho precarizado e da indústria de controle do crime nas áreas deserdadas tende a legitimar a afirmação e o reconhecimento de cidadanias diferenciadas.

Em relação ao Brasil, apesar de o país abrigar, como já foi dito, uma constituição democrática e um sistema de representação política pluripartidário, a realidade cotidiana do país ainda reflete a fragilidade dos mecanismos institucionais de controle social democrático sobre as instituições do Estado, a seletividade do sistema de justiça criminal e políticas de encarceramento em massa dos setores sociais pauperizados.

A produção de discursos políticos e ações institucionais restritas à crença na democracia representativa e na meritocracia individual como fator de mobilidade social esbarram - quando confrontados com a vida cotidiana de muitos adolescentes e jovens perturbados pela situação de pobreza, pelo fantasma do desemprego ou pelo trabalho precarizado, pela falta de acesso e permanência nos bancos escolares - em processos macroestruturais de reprodução da pobreza e de exclusão social. Neste contexto, que desafia a democratização da sociedade e do Estado brasileiro torna-se imperativo expor, debater e repensar, o alcance efetivo de políticas públicas sociais enquanto fator de reversão da pobreza e da exclusão social juvenil.

No caso dos jovens pobres, as políticas públicas nas quais eles figuram como públicoalvo parecem pouco atrativas no sentido de convencê-los a optar por formas legais de inserção no mercado de trabalho, uma vez que, na avaliação dos próprios jovens beneficiados, tais políticas não lhes asseguram possibilidades de êxito no mercado de trabalho, acesso à cultura de consumo, realização pessoal e reconhecimento social. A esse respeito, é oportuno reproduzir algumas informações sobre os adolescentes beneficiados pelo Programa Nacional de Inclusão de Jovens (ProJovem Urbano) ${ }^{2}$.

Tabela 1 - Alunos ingressantes e desistentes do ProJovem Urbano na cidade de Curitiba-PR, 2013

\begin{tabular}{|l|r|}
\hline SITUAÇÃO DOS ALUNOS INSCRITOS NO PROJOVEM URBANO & TOTAL DE ALUNOS \\
\hline Inscritos & 600 \\
\hline Desistentes & 200 \\
\hline Matriculados & 490 \\
\hline Frequentando & 150 \\
\hline Recebendo Bolsa & 90 \\
\hline
\end{tabular}

Fonte: Freire (2013), Lima (2014)

As informações acima, ainda que não sejam conclusivas, evidenciam a urgência de repensar o escopo das políticas governamentais de inclusão juvenil. Segundo Lima, a 
"maioria dos jovens consultados afirma que o recebimento de uma bolsa mensal no valor de 100 reais é o principal motivo para a permanência e frequência ao programa" (LIMA, 2014, 326-327).

No caso das políticas públicas de inclusão socioprofissional ou da aplicação das medidas socioeducativas, por exemplo, as instituições públicas e os peritos do Estado deveriam militar na defesa de espaços institucionais abertos à participação dos sujeitos-alvos e demais interessados, atribuindo-lhes o direito à fala e poder de decisão, uma vez que aspectos relativos à escolha profissional, ou à medida socioeducativa considerada mais justa e adequada à reparação de um determinado conflito, poderá definir o futuro profissional e o campo das relações sociais dos jovens em questão.

Nesta direção, a Organização das Nações Unidas (ONU) recomenda que países como o Brasil reorientem suas políticas criminais encarceradoras e encorajem iniciativas institucionais que contemplem a participação direta das partes em conflito, ou seja, a presença das figuras do infrator, da vítima e da comunidade como forma de solução pacífica dos atos que provocam danos materiais, agressão física, moral e simbólica. Dentre as recomendações sugeridas, a ONU menciona a justiça restaurativa como alternativa político-institucional alinhada à defesa e proteção dos direitos humanos. Antes de apresentar um breve histórico sobre a justiça restaurativa, é importante dimensionar a persistência de alguns desafios político-teóricos que dificultam a superação do paradigma político criminal penalizador.

\section{Do paradigma político-criminal penalizador à viabilidade das práticas de justiça restaurativa: uma breve contextualização histórica}

Segundo Melo (2005, p. 57), o direito à coerção é balizado pelo discurso filosófico racionalista de Kant que reporta à "questão do respeito ao dever para fundamentar a liberdade como expressão de adesão a uma máxima universal”, cujo obstáculo impõe a necessidade incondicional do castigo. Segundo o autor, este modelo de pensamento racional iluminista vinculado à justiça retributiva requer:

[...] a construção de um sistema e de uma regra aplicável a toda e qualquer circunstância, independentemente dos objetos externos, dos sentidos, dos desejos, das expectativas, expressa, inegavelmente, um valor subjacente: o de ordem, controle, fixidez, segurança, colocado de modo inquestionado como uma verdade por si mesma evidente. A necessidade do castigo, num sistema como tal, decorre da estruturação rígida de um modelo lógico de concepção da sociedade, fundada em valores tais que, para fazer valer sua universalidade, qualquer erro ou desvio deve ser extirpado. (MELO, 2005, p.57-58).

Assim, o raciocínio iluminista que serve de base à estruturação lógica do direito formal abstrato exige que este seja "pensado logicamente, [operado] coercitivamente [e teça] horror à 
transitoriedade, à mudança e ao movimento, ao incomensurável, à diferença, em suma, [aos] sentimentos que aparecem em toda situação de conflito". No plano ideológico, a ordenação do modelo jurídico penal abriga "uma ordem moral fundada na culpa e no castigo" que, além de ocultar estratégias de dominação, considera inevitável retribuir o sofrimento e imputá-lo como algo "natural, aceitável, desejável”. (MELO, 2005, p.58-59). No plano da realidade cotidiana, o direito estatal se realiza dentro de uma arquitetura judiciária conhecida por ostentar suntuosidade e externalizar relações hierárquicas de poder. Em relação ao direito formal abstrato, Salm e Leal (2012) recorrem aos argumentos de Morrison para enfatizar que todo formalismo é regulador uma vez que os "problemas e respostas são predeterminados [via] códigos de conduta, leis, regras de compromisso [e requerem] um julgamento moral acerca da gravidade da ação e um julgamento legal sobre o castigo apropriado". (MORRISON apud SALM; LEAL, 2012, p. 196-203).

Além disso, é preciso considerar a interferência de obstáculos político-acadêmicos que dificultam a aceitação da justiça restaurativa, provenientes de interesses burocráticocorporativos e da apropriação de capital universitário que atribui, aos peritos sociais e jurídicos, um rol de competências acadêmicas específicas cuja finalidade é assegurar, via expedição de um diploma reconhecido pelo Estado, o monopólio legítimo de um conjunto de saberes e técnicas que caracterizam o funcionamento verticalizado das instituições públicas. Sobre isso, escreve Bourdieu (2004, p.182), "uma das propriedades distintivas do campo acadêmico é delimitar o raio de ação, competência e hierarquia entre os agentes inseridos no campo e, ao fazê-lo, desqualificar e etiquetar os não iniciados como leigos e ignorantes". Nesse sentido, estratégias inclusivas de participação popular, de horizontalização do poder e adeptas a formas não punitivas de encaminhamento e solução de um determinado conflito, supõem reconhecer, para além da competência acadêmica, outros saberes, sujeitos e espaços comunitários como forma de encaminhamento e solução dos problemas que afetam a vida dos jovens e da comunidade.

No que tange às formas de participação popular no encaminhamento e desfecho dos conflitos, Jaccoud (2005) argumenta que o surgimento das sociedades industriais, caracterizadas pelo imperativo das monarquias de direito divino e pela centralização do poder do Estado, reduziu "consideravelmente [as] formas de justiça negociada" que faziam parte do modelo de organização das sociedades comunais europeias e coletividades nativas. Segundo o autor, os contextos, econômico, político e sociocultural das sociedades pré-estatais eram caracterizados pelo predomínio de interesses coletivos sobre os individuais. A ocorrência de determinados conflitos bem como as modalidades de resolvê-los demandavam um conjunto de "práticas de regulamento social centradas na manutenção da coesão do grupo" e, por este motivo, aquelas sociedades são consideradas precursoras da justiça restaurativa. (JACCOUD, 2005, p.164-165).

Nas sociedades contemporâneas, o ressurgimento do interesse pela justiça restaurativa vincula-se a uma complexa conjuntura que abarca, desde a contribuição acadêmica da Escola de Chicago, passando pela contestação das instituições repressivas, pela redescoberta da vítima no póssegunda guerra mundial e pela exaltação da comunidade local no encaminhamento dos conflitos 
sociais urbanos. Segundo Jaccoud (2005), o atual contexto de desagregação do modelo estatal de bem-estar social, aliado à crescente diferenciação e maior complexidade das relações sociais, do simbolismo jurídico, do maior protagonismo da sociedade civil e da "fragmentação dos centros de decisões”, pressiona o Estado a reorientar o seu foco de ação. A nova estratégia político-penal do Estado procura dar publicidade ao enfrentamento de delitos mais graves como latrocínios, sequestros, homicídios e, ao mesmo tempo, deixar em aberto e sem perspectiva de soluções concretas, a ocorrência de uma miríade de crimes comuns como furtos, arrombamentos e agressões não letais.

É oportuno esclarecer que a justiça restaurativa enquanto processo educativo, alinhada ao imperativo da participação popular e à descentralização do poder na gestão dos conflitos, opõese ao escopo de reformas políticas neoliberais tributárias da teoria da escolha racional. Segundo Garland (1999), uma das tendências do Estado neoliberal em curso é justificar a erosão da lei penal a uma suposta questão de oportunidade racional dos agentes transgressores, com o intuito de corresponsabilizar a sociedade civil e terceirizar a prevenção e controle do crime. A opção por espaços restaurativos que promovam o protagonismo da vítima, da figura do agressor e da comunidade local, enquanto potencialidade de promoção dos direitos humanos dentro e fora da administração da justiça, não significa, em absoluto, admitir que iniciativas de práticas restaurativas substituam o espaço "vazio deixado pela retirada progressiva do Estado em suas atividades" no campo da segurança pública e no fomento das políticas sociais (JACCOUD, 2005, p.166).

\section{Justiça restaurativa enquanto processo educativo e forma de saber-fazer interessada}

Um processo educativo na perspectiva de Paulo Freire (1994), no qual se vê similaridade com a justiça restaurativa, implica três principais aspectos: a construção de saberes numa perspectiva dialógica, numa dinâmica de troca, considerando que de ambos os lados existem saberes para compartilhar; a prática social em si leva à construção da consciência; e a ação educativa que se constrói em conexão com o entorno social. A este respeito, escrevem Freire e Macedo (1994, p. 31): "Ler a palavra e aprender como escreve a palavra, de modo que alguém possa lê-la depois, são precedidos do aprender como 'escrever' o mundo, isto é, ter a experiência de mudar o mundo e de estar em contato com o mundo". O processo educativo leva, por si próprio, a uma reflexão crítica da realidade. Segundo Freire (1997, p. 24), “[a] reflexão crítica sobre a prática se torna uma exigência da relação Teoria/Prática sem a qual a teoria pode ir virando blábláblá e a prática, ativismo".

O processo educativo, na perspectiva do autor, implica em saberes adquiridos que se configuram como instrumentos de construção da autonomia do sujeito. Embora o processo educativo se relacione inicialmente à alfabetização, o autor deixa implícito que tal processo vai para além do aprender a ler e a escrever, ou seja, para uma dimensão cultural, uma vez que "não se pode desenvolver um trabalho de alfabetização fora do mundo da cultura, porque a educação é, por si mesma, uma dimensão da cultura” (FREIRE, 1994, p. 33). 
Ao referir-se ao conceito de processo educativo, o autor afirma que este se constrói numa dimensão de coletividade e não da individualidade, no contexto de um entorno social, no espaço público, onde as regras sociais se explicitam em arenas deliberativas, como prevê as ações vinculadas à ideia de justiça restaurativa. A autonomia como princípio educativo, alinhada à ideia de justiça restaurativa, é outro ponto importante ressaltado por Paulo Freire. Para o autor, um verdadeiro processo educativo leva à construção da autonomia entendendo-se esta como a capacidade crítica da leitura do mundo e do real vivenciado. A educação para a autonomia se constrói a partir de conteúdos compartilhados e discutidos coletivamente, facilitando a construção da consciência crítica e superação da passividade do sujeito. Sob este ponto de vista, Saviani (2011) acrescenta contribuições importantes para a interface entre o processo educativo e a justiça restaurativa. Enquanto esta enfatiza o imperativo da corresponsabilização individual e coletiva dos envolvidos na solução de um determinado conflito - o processo do aprender não diz respeito a apenas um indivíduo, como se faz normalmente na escola tradicional - as reflexões do autor evidenciam que o processo educativo, no contexto escolar, deve ir além do conteúdo estudado e propiciar desenvolvimento intelectual e social, de modo a potencializar a pessoa do educando como sujeito das transformações sociais. Em outras palavras, a compreensão do processo educativo, enquanto construção social e política, facilita a elaboração da consciência crítica e da autonomia do sujeito, condições para a aceitação e o exercício da justiça restaurativa.

Autores como Scuro Neto (s.d.), Prudente e Sabadell (2008) argumentam que a justiça restaurativa constitui um sistema teórico-valorativo fundamentado nos princípios de corresponsabilidade de todos os envolvidos na infração (vítima, infrator e demais interessados) na busca de respostas e soluções que causaram o dano ou a agressão. Pressupõe, ao contrário do modelo político-jurídico centrado na ideia abstrata de crime-punição, participação comunitária e edificação de relações horizontais de poder, incluindo o poder jurisdicional. Considera que as pessoas, as famílias e a comunidade tenham algo mais a dizer em face de um "mundo dominado pelos grandes negócios, por políticos profissionais e tecnocratas" portadores de uma suposta consciência superior (SCURO NETO, s.d).

A criação de espaços de participação e deliberação é uma forma de redefinir a lógica de distribuição do poder e de ressignificar o modelo convencional de democracia representativa considerada, muitas vezes, passiva, estática e limitada a convidar as pessoas a confiarem na justiça e proteção do Estado.

A reivindicação de ideias e ações comprometidas em reinventar o modelo tradicional de organização social e de democracia, escreve Bourdieu, significa ter em mente que as sociedades contemporâneas:

[...] se apresentam como espaços sociais, isto é, estruturas de diferenças que não podemos compreender verdadeiramente a não ser construindo o princípio gerador que funda essas diferenças na objetividade. [O princípio gerador refere-se à] estrutura da distribuição das formas de poder ou dos tipos de capital eficientes no universo social considerado. (BOURDIEU, 2007, p.50). 
Nesta direção, a justiça restaurativa entende que a potencialidade do poder é "gerada pela associação, não pela força" e, como consequência, pressupõe a reconstrução do "paradigma de justiça a partir da participação do poder". O pressuposto da participação popular ressalta a importância da democracia deliberativa aberta ao "empoderamento dos indivíduos produtores de saberes a respeito de "suas próprias vidas e da comunidade na qual se inserem". A ideia é que os saberes em questão devam tornar-se "relevantes, reconhecidos" e utilizados na arena decisória via compartilhamento e "coprodução de sociabilidade, de histórias e de justiça". (MORRISON apud SALM; LEAL, 2012, p.197). No tocante à abrangência territorial, o foco da justiça restaurativa é a microssociedade que se constitui nas escolas, nas instituições públicas, nas famílias e nas comunidades. No caso dos conflitos que demandam a intervenção do Poder Judiciário, os modelos restaurativos buscam subverter lógicas monopolizadoras "que tem possibilitado a manutenção da justiça como figura burocrática, [...] opressora [e] legitimadora de um suposto Estado de Direito" (SALM; LEAL, 2012, p.197-200).

A preocupação neste caso é:

[...] transformar os espaços decisórios em cenários menos burocráticos [de tal modo que o Estado deixe] de ser o órgão central da estrutura social e regulatória, para se tornar, na melhor das hipóteses, contribuinte de uma dinâmica sócio e culturalmente construída de emancipação e sociabilidade. (SALM; LEAL, 2012, p.197).

A exigência de redefinição dos espaços decisórios deve-se ao fato de a justiça restaurativa estar essencialmente ligada ao exercício de "práticas democráticas [que exigem] organizações [...] democráticas". Por isso, não é possível enquadrar os modelos restaurativos de solução de conflitos "dentro [da arquitetura] do poder estatal" e, tampouco, "falar em espaços restaurativos algemando pessoas". (SALM; LEAL, 2012, p. 196-203).

$\mathrm{O}$ ativismo democrático de base comunitária, que apregoa o envolvimento direto da comunidade local e a descentralização do poder, é concebido como estratégia de revitalização das práticas de aprendizagem e de corresponsabilização da comunidade na escolha dos procedimentos que irão incidir nas decisões sociojurídicas de reparação dos conflitos sem, contudo, excluir iniciativas democráticas e sensibilizadoras por parte das autoridades estatais.

O reconhecimento das relações de poder como atributo das relações, reforça a importância de processos aliados a projetos coletivos que revertam a desigualdade. Entende-se que o processo de conquista de direitos, no sentido da emancipação humana, não ocorre e nem ocorrerá pelo mero estabelecimento de sistemas normativos, mas pela atuação de sujeitos comprometidos com a defesa e ressignificação dos direitos humanos, capazes de potencializar a incidência de tais direitos no campo da criação e efetivação das políticas públicas. Neste sentido, torna-se essencial o fortalecimento da esfera sociopolítica, da emancipação política, da participação social.

Ao lado de entraves políticos e estruturais que impedem e/ou dificultam a superação da pobreza e da desigualdade na partilha da renda, poder e riqueza, a institucionalidade das políticas 
públicas ainda conforma um cenário de ações predominantemente residuais e fragmentadas e, como tal, desafia a gestão pública na formulação de políticas públicas universais e indivisíveis para a proteção dos direitos humanos.

Num contexto econômico, político e social permeado pela cultura antidemocrática e legitimação de instituições e padrões tradicionais, observa-se, ainda, uma reivindicação velada ou direta de parte da sociedade por um Estado mais criminalizador. Neste caso, o apelo por soluções punitivas concorre com práticas humanizadoras que buscam ressignificar valores e práticas democrático-participativas.

A justiça restaurativa diz respeito, portanto, não apenas à capacidade de mobilização e envolvimento das partes diretamente afetadas, mas da construção de uma rede de sociabilidade que contemple a presença de lideranças comunitárias e técnicos sociais, Organizações não Governamentais, pastorais religiosas, etc., com a finalidade de demonstrar, na prática, a viabilidade de mecanismos sociojurídicos mais democráticos, participativos, deliberativos, justos e eficazes na solução dos conflitos juvenis. Ao mesmo tempo, o desenvolvimento de novas tecnologias sociais no campo sociojurídico, orientadas pela justiça restaurativa, aliada ao desenvolvimento de políticas públicas territorializadas de redução das desigualdades, tende a potencializar novos projetos de vida, contribuir para a interrupção de ciclos de violência e reativar processos emancipatórios.

\section{Considerações finais}

Em face do contexto econômico e sociocultural que amplia as desigualdades sociais, acelera as mudanças culturais e aprofunda a descrença juvenil nas formas de representação política e na capacidade de controle das instituições verticalizadas, as sociedades e suas instituições são levadas a refletir e a pleitear novas formas de representação política e participação social capazes de oferecer mecanismos sociojurídicos mais democráticos, legítimos e eficazes na solução dos conflitos que afligem e violam, de maneira mais cruel e dramática, os direitos humanos da juventude pobre em situação de vulnerabilidade social.

Com esse propósito, as práticas restaurativas de solução dos conflitos buscam ampliar, não apenas o conteúdo democrático de reconhecimento à pluralidade de interesses, valores e identidades que circulam na sociedade, mas repensar a existência e a continuidade de modelos mentais e práticas institucionais punitivas e centralizadoras como atestam o atual aparato políticopenal de solução dos conflitos. Os modelos restaurativos representam uma alternativa viável e duradoura de solução dos conflitos sempre que reconhecer uma gama de valores e formas de lidar com as situações problemáticas cujos significados extrapolam a rigidez formal de termos ambíguos definidos como ato infracional, adolescente infrator, culpabilidade e castigo. As práticas restaurativas, ao enfatizarem possibilidades não punitivas de solução dos conflitos, predispõemse a aceitar e experimentar outras formas de responsabilização e reparação individual dos atos de agressão sem, contudo, deixar de reconhecer que a figura do agressor não é insensível às noções 
de liberdade, responsabilidade, desejo e autonomia; capacidade de reconhecer, contextualizar circunstâncias e reparar, sem o estigma da interdição e do medo, as consequências dos seus atos gravosos contra as pessoas e a comunidade. Trata-se, portanto, de uma prática que demanda um processo educativo capaz de romper com tendências teórico-metodológicas unilaterais. Esta é uma condição para a abertura de novos caminhos de conexão entre justiça social e inserção dos diferentes sujeitos na troca de diferentes saberes e experiências construídos no mundo da vida, processo que alimenta e fortalece a democracia e o horizonte desejável da emancipação humana.

Em síntese, a justiça restaurativa na perspectiva de um processo educativo, no sentido de uma ação construída no contexto do espaço social, possibilita ao sujeito superar a condição passiva que, muitas vezes, é-lhe imposta por ordenamentos institucionais hierárquicos e punitivos, levando-o a agir como indivíduo ativo e autônomo, consciente da sua ação e, como tal, coprodutor de respostas aos problemas que lhe dizem respeito e demandam soluções dialogadas, coletivas e antirrepressivas.

\section{Referências bibliográficas}

BARATTA, Alessandro. Criminologia crítica e crítica do direito penal: introdução à sociologia do direito penal. 3. ed. Rio de Janeiro: Revan, 2002.

BAUMAN, Zygmunt. Vida Líquida. Rio de Janeiro: Zahar, 2007.

BONETI, Lindomar W. Educação para a Justiça Social, Agentes insurgentes e a crise do instituído. Revista Diálogo Educacional, v. 16, n. 47. Curitiba: PPGE/PUCPR, p. 59-76, 2016

BOURDIEU, Pierre. Coisas ditas. São Paulo: Brasiliense, 2004.

. Razões práticas: sobre a teoria da ação. 8. ed. Campinas, SP: Papirus, 1997.

BRASIL. Decreto-Lei n. 8.118, de 10 de outubro de 2013. Altera o Decreto no 7.721, de 16 de abril de 2012, que dispõe sobre o condicionamento do recebimento da assistência financeira do Programa de Seguro-Desemprego à comprovação de matrícula e frequência em curso de formação inicial e continuada ou de qualificação profissional, com carga horária mínima de cento e sessenta horas. Presidência da República. Disponível em: http://www.planalto.gov.br/ccivil_03/_ato2011-2014/2013/decreto/D8118.htm.

Ministério da Justiça. Departamento Penitenciário Nacional/DEPEN. 2016. Disponível em: http://www. justica.gov.br/news/ha-726-712-pessoas-presas-no-brasil/relatorio_2016_junho.pdf. Acesso em 1 mai. 2018. CARBALLIDO, Manuel Eugénio Gándara. Repensando los Derechos Humanos desde las luchas. Revista de Direitos Fundamentais e Democracia, Curitiba, v. 15, n. 15, p. 41-52, janeiro/junho de 2014.

DE VITTO, Renato Campos Pinto. Justiça Criminal, Justiça Restaurativa e Direitos Humanos. In: SLAKMON, C.; DE VITTO, R.; GOMES PINTO, R. (org.). Justiça Restaurativa. Brasília: Ministério da Justiça e Programa das Nações Unidas para o Desenvolvimento (PNUD), 2005.

FREIRE, Joice A. Políticas Públicas para jovens não universitários. Programa Institucional de Bolsa de Iniciação Científica (PIBIC). PUCPR, 2012-2013.

FREIRE, Paulo. Pedagogia da Autonomia: saberes necessários à prática educativa. 50. ed. Rio de Janeiro: Paz e Terra, 1997. Pedagogia do Oprimido. 50. ed. Rio de Janeiro: Paz e Terra, 2011.

; MACEDO, Donaldo. Alfabetização: leitura do mundo, leitura da palavra. Rio de Janeiro: Paz e Terra, 1994. GARLAND, David. As contradições da "sociedade punitiva”: o caso britânico. Revista Discursos Sediciosos: Cri- 

ao itinerário penalizador dirigido aos jovens da periferia urbana

me, direito e sociedade (Instituto Carioca de Criminologia). Rio de Janeiro, v.11, 1 set. 2002.

Human Rights Watch. Força letal: violência policial e segurança pública no Rio de Janeiro e em São Paulo. dez. 2009. Disponível em: https://www.hrw.org/sites/default/files/reports/brazil1209ptwebwcover.pdf. Acesso em: 2 nov. 2015.

JACCOUD, Mylène. Princípios, tendências e procedimentos que cercam a Justiça Restaurativa. In: BASTOS, Márcio Thomaz; LOPES, Carlos; RENAULT, Sérgio Rabello Tamm (Orgs.). Justiça Restaurativa. Coletânea de Artigos. Brasília: MJ e PNUD, 2005. Disponível em: www.justica21.org.br/interno.php?ativo=BIBLIOTECA.

LIMA, Cezar Bueno. Jovens em conflito com a lei: liberdade assistida e vidas interrompidas. Londrina: EDUEL, 2009. Juventude e políticas públicas: entre proibições, trabalho sub-remunerado e novas práticas de sociabilidade.

Mediações - Revista de Ciências Sociais, v.19, n. 1, p.317-336, 2014.

MARSHALL, Thomas. Cidadania, Classe Social e Status. Rio de Janeiro: Zahar Editores, 1998

MELO, Eduardo Rezende. Justiça restaurativa e seus desafios histórico-culturais Um ensaio crítico sobre os fundamentos ético-filosóficos da justiça restaurativa em contraposição à justiça retributiva. In: SLAKMON, C.; DE VITTO, R.; GOMES PINTO, R. (org.). Justiça Restaurativa. Brasília : Ministério da Justiça e Programa das Nações Unidas para o Desenvolvimento (PNUD), 2005.

ONU. Assembleia Geral das Nações Unidas. Resolução 2002/12- Princípios Básicos para Utilização de Programas de Justiça Restaurativa em Matéria Criminal. Disponível em: http://www.arcos.org.br/livros/estudos-de-arbitragem-mediacao-e-negociacao-vol4/parte-vi-miscelanea/nacoes-unidas-conselho-economico-e-social. Acesso em 17/05/2018.

PASSETTI, Edson. Anarquismos e sociedade de controle. São Paulo: Cortez, 2003.

PRUDENTE, Neemias M.; SABADELL, Ana L. Mudanças de paradigmas: justiça restaurativa. Maringá/PR. Revista Jurídica Cesumar, v. 8, n. 1, p. 49-62, jan./jun. 2008.

SALM, João; LEAL Jackson da Silva. A Justiça Restaurativa: multidimensionalidade humana e seu convidado de honra. Sequência, n. 64, p. 195-226, jul. 2012. Disponível em: https://periodicos.ufsc.br/index.php/sequencia/article/view/2177-7055.2012v33n64p195. Acesso em:

SAVIANI, Dermeval. Pedagogia Histórico-Crítica: Primeiras Aproximações. 11. ed. Campinas: Autores Associados, 2011.

SCURO NETO, Pedro. Movimento restaurativo e a justiça do século XXI. Disponível em: http://jij.tjrs.jus.br/ justica-restaurativa/movimento-restaurativo Acesso em: 28 jun. 2007.

WACQUANT, Loïc. A estigmatização territorial na cidade da marginalidade avançada. [2006]. Disponível em: http://ler.letras.up.pt/uploads/ficheiros/4618.pdf. Acesso em 17 fev. 2015.

. As prisões da miséria. Rio de Janeiro: Zahar, 2001.

WAISELSZ, Julio Jacobo. Mapa da Violência 2012: Crianças e Adolescentes do Brasil. [2012]. Disponível em http:// www.mapadaviolencia.org.br/pdf2012/mapaviolencia2012_Criancas_e_Adolescentes.pdf. Acesso em 23 jan. 2015.

Mortes matadas por armas de fogo. Secretaria Geral da Presidência da República. Secretaria Nacional de Juventude/Secretaria de Políticas de Promoção da Igualdade Racial. [2015]. Disponível em: http://www.mapadaviolencia.org.br/pdf2015/mapaViolencia2015.pdf. Acesso em: 18 mar. 2016.

Recebido em 12/01/2017

Aceito em 11/05/2018 